1Secretaria Municipal de Saúde do Rio de Janeiro (SMS-RJ) - Rio de Janeiro (RJ), Brasil.

mariana_almeida83@yahoo. com.br

2 Universidade do Estado do Rio de Janeiro (Uerj), Faculdade de Enfermagem, Departamento de Enfermagem em Saúde Pública - Rio de Janeiro (RJ), Brasil.

helenalealdavid@gmail.com

3 Instituto Brasileiro de Informação em Ciência e Tecnologia (lbict) e Universidade Federal do Rio de Janeiro (UFRJ), Programa de PósGraduação em Ciência da Informação - Rio de Janeiro (RJ), Brasil. regina.mar2@gmail.com

\section{Redes sociais de usuários portadores de tuberculose: a influência das relações no enfrentamento da doença}

\author{
Social networks of users with tuberculosis: the influence of \\ relationships in coping with the disease \\ Mariana de Almeida Jorge de Azevedo', Helena Maria Scherlowski Leal David², Regina Maria \\ Marteleto 3
}

DOI: $10.1590 / 0103-1104201811708$

RESUMO Redes sociais é um conceito polissêmico utilizado para estudar as relações sociais estabelecidas pelo sujeito com indivíduos e/ou organizações possibilitando a construção de uma teia de relacionamentos por meio de elos e conexões. Este estudo tem como objeto as redes sociais de pessoas portadoras de tuberculose acompanhadas em uma unidade de Atenção Básica na Área Programática 3.1 do município do Rio de Janeiro. O estudo das redes sociais dos usuários possibilitou compreender a busca pelo cuidado em saúde como um processo que envolve diversos aspectos que atuam de maneira distinta sobre os indivíduos, além de vislumbrar o potencial da estrutura das redes para o cuidado em saúde.

PALAVRAS-CHAVE Tuberculose. Redes sociais. Saúde da família.

ABSTRACT Social network is a polysemic concept used to study the social relations established by the subject with individuals and/or organizations making possible the construction of a network of relationships through links and connections. This study aims at the social networks of people with tuberculosis attended in a Primary Care unit in Program Area 3.1 of the city of Rio de Janeiro. The study of the users' social networks made it possible to understand health care as a process that involves several aspects that act in different ways on the users, as well as to glimpse at the potential of the structure of networks for health care.

KEYWORDS Tuberculosis. Social networking. Family health. 


\section{Introdução}

A Tuberculose (TB) continua sendo mundialmente considerada um problema de saúde pública, permanecendo como a principal causa de morte por doença infectocontagiosa em adultos. Sua ocorrência está associada à pobreza, às más condições de vida e de habitação e à aglomeração humana, sendo o Brasil um dos países com o maior número de casos no mundo ${ }^{\mathbf{1 , 2}}$.

Desde 2003, a doença é considerada como prioritária na agenda política do Ministério da Saúde (MS). Desenvolvido por intermédio de um programa unificado, executado em conjunto pelas esferas federal, estadual e municipal, o Programa Nacional de Controle da Tuberculose (PNCT) prioriza a descentralização das medidas de controle para a atenção básica, visando à ampliação do acesso da população em geral e dos grupos mais vulneráveis. Essa descentralização diz respeito ao reconhecimento da Atenção Básica (AB) como protagonista na coordenação do sistema de atenção à saúde por meio do gerenciamento de mecanismos organizacionais e materiais que possam garantir a longitudinalidade do cuidado ${ }^{3}$.

Entre diversas atribuições, as Equipes de Saúde da Família (EqSF) devem abordar as pessoas portadoras de TB dentro das áreas geográficas de atuação, desde a suspeita clínica, passando pelo encaminhamento para a investigação diagnóstica ao acompanhamento dos casos confirmados, por meio do tratamento supervisionado e da coleta de baciloscopia mensal de controle, garantindo a longitudinalidade do cuidado, característica central desse nível assistencial ${ }^{2}$.

O caráter ainda estigmatizante da TB e as condições sociais precárias da maioria dos portadores exigem das EqSF o compromisso, o envolvimento e o reconhecimento do impacto causado pela doença nas dimensões física, social, psicológica, econômica e espiritual, sendo importante a percepção dessas questões e o entendimento da sua possível influência na busca pelos serviços de saúde ${ }^{4}$.
Reconhecer que a condição de saúde e a procura pelos serviços estão vinculadas ao contexto e singularidades dos indivíduos reforça a importância das EqSF se organizarem de modo a servir como a principal referência dos usuários na busca pelo cuidado em saúde. Essa responsabilidade sustenta-se nos princípios norteadores da Estratégia Saúde da Família (ESF) que também visam à construção de uma relação profissional-paciente sólida, a saber: universalidade, acessibilidade, vínculo, continuidade do cuidado, integralidade da atenção, responsabilização, humanização, equidade e participação social5.

Mesmo sendo a unidade de $A B$ o serviço mais indicado para responder a questões relacionadas com a saúde do indivíduo, é preciso, primeiramente, considerar que as escolhas que geram ações acerca do processo de adoecimento são influenciadas por questões subjetivas individuais e coletivas que se apoiam em aspectos e contextos variados, como os socioculturais. Desse modo, compreende-se que os caminhos trilhados por pessoas em busca de assistência à saúde nem sempre coincidem com os fluxos ou esquemas preestabelecidos em protocolos clínicos ${ }^{6}$.

Por esse ângulo, torna-se importante destacar o conceito de redes utilizado pelas ciências sociais, que se refere à sociedade como um conjunto diverso de relações e funções que os indivíduos desempenham uns em relação aos outros. Em sociedades complexas, essas relações tornam-se interdependentes, vinculando-se e formando cadeias de atos ligados a outros laços invisíveis?.

As relações como as de familiaridade, parentesco, vizinhança e amizade que se estabelecem pelo processo de socialização do indivíduo, ao longo da vida, de forma autônoma, espontânea e informal, podem ser entendidas como redes primárias. Já as redes que apresentam um interesse comum, formadas pelo desempenho coletivo de um grupo, instituição e movimento, são compreendidas como redes secundárias ${ }^{8}$.

Rede social refere-se às relações sociais 
estabelecidas pelo sujeito com indivíduos e/ ou organizações possibilitando a construção de uma teia de relacionamentos por meio de elos e conexões, em que é possível analisar os papéis exercidos por cada ator a partir de interesses e objetivos comuns. Está relacionada com a dimensão estrutural e institucional ligada ao indivíduo, 9,0.

Estudos como o realizado na África por Janzen (1978) citado por Alves e Souza"1 mostram a influência das redes sociais na análise interativa do itinerário terapêutico devido a sua capacidade de realizar conexões com as instituições de saúde, fato este percebido a partir do mapeamento das relações entre os indivíduos ou grupos e da análise dos papéis dos sujeitos que as compõem ${ }^{11}$.

Tais redes sociais, sejam elas formais ou informais, estabelecem-se a partir da confiança entre seus agentes, com o gozo de vantagens geradas pelo conhecimento, como, por exemplo, obtenção de informações e outros recursos que resultam de ações instrumentais. Desse modo, é possível compreender que o capital social oriundo das relações estruturais existentes, formado por um conjunto de normas, pode afetar positivamente uma comunidade visto que a cooperação entre seus membros pode ajudar a reduzir o custo da obtenção de informação ${ }^{12}$.

A apropriação do pensamento do sociólogo francês Pierre Bourdieu com base nas formas sociais de produção da cultura, do conhecimento e da informação tem se mostrado importante nos estudos de redes haja vista o enfoque dado nas relações. Este construiu a noção de capital que se apresenta de quatro formas: a econômica, a cultural, a social e a simbólica, todas incluindo uma acumulação de disposições, habilidades e conhecimentos que permitem aos sujeitos participarem, em determinada posição, em um campo específico ${ }^{13}$.

Ao considerar o exposto, este artigo teve como objetivo estudar as redes sociais dos usuários portadores de $\mathrm{TB}$ acompanhados em uma unidade de AB na Área Programática
3.1 do município do Rio de Janeiro, no sentido de compreender como as relações exercem influência no enfrentamento da doença.

\section{Metodologia}

Trata-se de um estudo descritivo com abordagem qualitativa. O cenário deste estudo foi uma unidade de $\mathrm{AB}$ na Área de Planejamento (AP) 3.1 do município do Rio de Janeiro. A unidade selecionada foi uma clínica da família situada na Estrada do Itararé, em Ramos, que, desde abril de 2010, presta serviços à população adscrita, residente em áreas do Complexo do Alemão. Essa unidade possui 4 EqSF, 2 equipes de saúde bucal e, aproximadamente, 13.190 pessoas cadastradas ${ }^{\mathbf{1 4}}$.

Foram entrevistados 7 usuários portadores de TB que realizavam acompanhamento nessa unidade de atenção básica, entre estes, 5 homens e 2 mulheres.

Anteriormente à seleção dos participantes, foi realizada consulta ao 'Livro de registro e acompanhamento de tratamento dos casos de tuberculose'. Neste livro, foi possível confirmar o quantitativo de pessoas portadoras de TB vinculadas à unidade, que, no período da coleta de dados (de abril a maio de 2017), eram 24 pacientes; e as que estavam efetivamente realizando acompanhamento para TB na atenção básica, que eram 20 pacientes - os outros 4 por serem casos de TB Multidrogarresistente (MDR) realizavam acompanhamento em outro nível de atenção à saúde. Foram adotados os seguintes critérios de inclusão: ser portador de TB e realizar acompanhamento na unidade de atenção básica. Como critérios de exclusão: pacientes portadores de TB que estivessem realizando acompanhamento em outro nível de atenção à saúde. A aplicação desses critérios ocorreu visando contemplar usuários das quatro EqSF da unidade. Sendo assim, a partir dessa seleção, as entrevistas começaram a ser agendadas com os usuários, cabendo frisar que o tamanho da amostra se 
deu pela saturação teórica percebida com a realização da sétima entrevista.

Utilizou-se a narrativa de vida como técnica de coleta de dados. Esta visa verificar o significado que os sujeitos atribuem a situações cotidianas a partir da análise de percepções individuais, padrões universais de relações humanas, condutas e atitudes características de grupos sociais específi$\cos ^{15}$. A questão norteadora da entrevista foi: fale-me como foi a sua busca para iniciar o acompanhamento da $\mathrm{TB}$ na $\mathrm{AB}$ e das pessoas envolvidas nesse processo.

Outra técnica utilizada para a coleta de dados sociodemográficos a fim de traçar o perfil dos participantes foi um questionário desenvolvido para essa finalidade.

A análise dos dados consiste na apresentação das narrativas e das seguintes categorias: percepção dos sintomas e a busca pelo atendimento; o papel da rede primária no cuidado em saúde; rede secundária e o seu papel no controle da TB; os diversos capitais em jogo na rede.

Esta pesquisa foi pautada nos critérios que regulamentam os aspectos ético-legais da pesquisa envolvendo seres humanos definidos na Resolução n ${ }^{\circ} 466 / 2012$ do Conselho Nacional de Saúde (CNS). Ressalta-se que o projeto foi submetido ao Comitê de Ética em Pesquisa da Universidade Estado do Rio de Janeiro, e, posteriormente, encaminhado ao Comitê de Ética em Pesquisa Secretaria Municipal de Saúde do Rio de Janeiro (SMS/ $\mathrm{RJ}$ ), seguindo todos os preceitos éticos necessários para a sua realização, obtendo aprovação no dia 12 de abril de 2017 sob o parecer $\mathrm{n}^{\circ}$ 1.908.477.

\section{Resultados e discussão}

A análise irá aprofundar aspectos relativos às relações em rede e suas influências a partir das narrativas dos entrevistados. Para garantir o anonimato e preservar a identidade deles, seus nomes foram substituídos por adjetivos dados a partir da percepção da característica comportamental mais marcante percebida durante a realização da entrevista. Sendo assim, eles serão chamados de reservada, sociável, tímido, abatido, esperta, responsável e agitado.

\section{Percepção dos sintomas e a busca pelo atendimento}

$\mathrm{Na}$ forma pulmonar, o sintoma mais comum da TB é a tosse. Podendo ser inicialmente seca e, posteriormente, produtiva. Além da tosse, o indivíduo pode apresentar ainda: febre (geralmente baixa), sudorese noturna, emagrecimento, astenia (cansaço e mal-estar), emagrecimento, dor torácica, hemoptise e/ou escarro hemático ${ }^{2}$.

A partir da análise das narrativas, foi possível observar que a percepção pelo indivíduo do agravamento do seu quadro clínico, após uso ou não da automedicação ou medicamentos caseiros, relacionou-se com a motivação para busca ao serviço de saúde, influenciando assim no tempo decorrido até o diagnóstico da doença.

Foi possível notar que a persistência da tosse revelou uma condição de adoecimento não apenas para os que com ela sofriam, mas também afetou pessoas que os cercavam, seja pelo incomodo provocado pelo barulho, pelo fato de ver que seu ente estava sofrendo, ou até mesmo pelo fato de pensar na possibilidade de ser TB. O que se observou foi que esse sintoma serviu como um propulsor para a busca da resolução de um problema de saúde seja por meio do uso de medicamentos caseiros, automedicação ou recorrendo aos serviços de saúde.

Segundo o MS, a ESF deve assumir o papel de porta de entrada preferencial do usuário ao serviço de saúde, mas as narrativas apontam que a maioria dos entrevistados ('reservada', 'abatido', 'esperta', 'responsável', 'agitado') escolheu as Unidades de Pronto Atendimento (UPAs) como primeira opção na busca pela resolução imediata do seu problema de saúde. 
Isso se deve ao fato de essas unidades funcionarem 24 horas por dia, dispor de recursos de diagnóstico que podem definir a gravidade do quadro clínico do paciente e também pelo desconhecimento dos serviços oferecidos pelas unidades de atenção básica ${ }^{16}$.

Todavia, apesar da disponibilidade de insumos e métodos diagnósticos, alguns locais ainda apresentam dificuldade na detecção de casos de $\mathrm{TB}$, principalmente, pela não valorização da tosse como sinal clínico da doença, pela não solicitação da baciloscopia do escarro para diagnóstico ou por outras deficiências relacionadas com o acesso às ações e serviços de saúde ${ }^{17}$.

A dificuldade no diagnóstico evidenciou também a falta de reconhecimento da problemática da TB pelos profissionais de saúde e ainda mostrou a falha na comunicação com a clientela. Isso ocorre pelo fato de os profissionais de saúde ainda adotarem uma comunicação especializada, monológica e instrumental que não contempla o papel central da interação humana em si como possibilidade de enriquecimento mútuo, fazendo com que a possibilidade de influenciar comportamentos, de gerar questionamentos e de permitir uma escuta ativa se percam ${ }^{18}$.

A necessidade de qualificação dos profissionais dos serviços de saúde que funcionam como porta de entrada do usuário se torna fundamental para a detecção da doença e para o início do tratamento em tempo oportuno, rompendo assim com a cadeia de transmissão ${ }^{16}$. Contudo, além disso, as narrativas retratam o distanciamento entre as perspectivas dos profissionais e as da clientela em se tratando de resolução dos problemas de saúde, o que permite inferir a presença de falhas na escuta ativa. Não se pode, porém, minimizar como barreiras de comunicação apenas questões de 'conhecimento/desconhecimento', ou de facilitação da linguagem ou mesmo de níveis de escolaridade, mas sim divergência de interesses, e necessidades múltiplas em jogo, que influenciam a construção do conhecimento ${ }^{\mathbf{1 8}}$.
Correlacionando o contexto social que permeia a TB com o histórico de vida dos entrevistados, pode-se afirmar que o desencontro entre a perspectiva técnica e leiga aumenta com a ausência de iniciativas direcionadas à aproximação entre saberes, devido às posições que esses atores ocupam em situação de interlocução no interior das instituições de saúde, reforçando a dificuldade em aceitar que pessoas humildes e pobres sejam capazes de organizar e sistematizar pensamentos ${ }^{\mathbf{1 8}, 19}$.

\section{O papel da rede primária no cuidado em saúde}

Ao tomar como base a ideia de que o conceito de redes sociais é um conceito de junção, torna-se importante destacar a influência exercida pelas redes primárias no contexto da saúde, principalmente no que tange ao cuidado comunitário, lembrando que essas redes se formam a partir do processo de socialização do sujeito, podendo ser formadas por relações de familiaridade, parentesco, vizinhança e amizade ${ }^{8}$.

Pensando sob essa perspectiva, fica fácil compreender o motivo pelo qual todos os entrevistados citaram algum membro da família como potente influenciador não somente para a busca pelo cuidado em saúde, mas também exercendo papel fundamental no enfrentamento da doença.

Pesquisas têm destacado o papel da família e das redes sociais na atenção e promoção da saúde, principalmente no fortalecimento de relações que produzem saúde ou incrementam a capacidade de enfrentar situações críticas e mobilizar recursos adequados; no desenvolvimento da capacidade de manutenção e promoção de relações de suporte social; e na melhoria do acesso aos serviços de saúde, haja vista sua função de mediação e de conhecimento das oportunidades e dos critérios de acesso 20.

No caso de 'reservada', a sua cunhada não sabia há quanto tempo a entrevistada estava 
apresentando os referidos sintomas, mas percebeu a gravidade do seu estado de saúde e quis logo levá-la ao médico. A única pessoa com quem a paciente comentava sobre a persistência desse quadro era a sua irmã, que mora em São Gonçalo. Relatou que conversavam bastante sobre tudo e que essa irmã já havia orientado que ela buscasse atendimento médico. Essa paciente relata que o companheiro e a irmã, que moram com ela, apesar de estarem próximos fisicamente, não interferiram na busca pelo cuidado em saúde, mas a apoiam no enfrentamento da doença.

'Sociável' possui relação bastante harmoniosa com a irmã, sendo esta a pessoa com quem conversa sobre qualquer assunto e quem realmente o incentivou a buscar atendimento para resolver seu problema de saúde. O usuário fala também sobre sua relação com a sobrinha-neta de 14 anos, que o auxilia no cuidado à saúde, mas que também exerce atitude de controle. Ele possui dois filhos que moram no Complexo do Alemão e com os quais, atualmente, mantém uma boa relação. De modo geral, sinaliza que a convivência familiar é bem tranquila, passando por altos e baixos, o que para ele é normal.

‘Tímido' foi motivado pela mãe e pela irmã a buscar atendimento na unidade de saúde da família, sendo sempre acompanhado por uma das duas nos atendimentos lá realizados.

‘Abatido' destacou a importância da rede primária para a busca do cuidado em saúde. Na primeira e segunda vez que adoeceu por $\mathrm{TB}$, os familiares, principalmente o pai, a mãe e as duas irmãs que também moram na comunidade, exerceram papel de cuidadores. Foram as irmãs que o levaram ao serviço de saúde, visto que o seu estado não permitia que ele fosse sozinho. Já no acompanhamento atual, além dos familiares que o incentivaram, outras pessoas exerceram influência para que 'Abatido' buscasse o serviço de saúde, entre eles: amigos e uma vizinha.

Já para 'Esperta' a busca pelo cuidado em saúde foi influenciada pela mãe, que, percebendo a persistência dos sintomas, recorreu ao serviço de saúde. Após iniciado o tratamento para TB na ESF, além da mãe, outras pessoas da rede primária passaram a exercer o cuidado, dando suporte emocional e colaborando para a adesão ao tratamento e enfrentamento da doença, como: as irmãs, a tia e as amigas.

Inicialmente, 'Responsável' não comentou com ninguém o que estava sentindo: em casa, procurava tossir do lado de fora, e quando sua esposa perguntava se estava sentido algo, ele desconversava, visto que não queria preocupá-la. Foi ao Posto de Atendimento Médico (PAM) de Del Castilho, UPA, comprou xarope e não falou nada, mas, quando viu a presença de sangue no escarro, comentou com sua companheira, e ela imediatamente o incentivou a procurar um médico.

‘Agitado' desde o início comentou com familiares sobre a dor que estava sentindo em região precordial. Como também apresentou tosse - e como seu irmão mais velho, que reside em outro local, também já teve TB -, sua mãe logo suspeitou que pudesse estar com a mesma doença e quis logo marcar uma consulta na clínica da família. Depois que sua mãe falou que poderia ser TB, 'Agitado' ficou ainda mais preocupado e recorreu à internet para pesquisar sobre a doença, já que achava que não estava apresentando os sintomas mais comuns.

Além de a família tê-lo incentivado a buscar atendimento, ele relata que viu um vizinho muito emagrecido e que depois soube que era devido à TB, e isso também o fez pesquisar sobre as dores que estava sentindo e buscar o atendimento médico.

\section{Rede secundária e o seu papel no controle da tuberculose}

Sendo consideradas redes secundárias, as unidades de saúde têm papel fundamental na relação com as redes primárias para juntas conseguirem agir sobre os determinantes coletivos dos problemas de saúde, sem tirar a responsabilidade das pessoas ante o processo 
de adoecimento, assegurando assim uma assistência integral e resolutiva ${ }^{8}$.

As narrativas analisadas demonstraram a importância do vínculo como importante princípio do cuidado, visto que possibilitou a construção de uma relação de confiança, diálogo e respeito entre o profissional de saúde e o paciente, contribuindo assim para a aceitação do diagnóstico, compreensão da terapêutica adotada e adesão ao tratamento ${ }^{2}$.

O Tratamento Diretamente Observado (TDO), tratamento padronizado com a supervisão da tomada da medicação e apoio ao paciente, mostrou-se como uma importante estratégia para o desenvolvimento das relações de acolhimento, vínculo e de corresponsabilização do doente perante o tratamento, sendo um ponto essencial no processo de adesão à terapia.

Na maioria dos casos, a TB é um problema de resolução na $\mathrm{AB}$, mas para isso, as equipes de saúde devem ser capacitadas para atuar de maneira eficaz na investigação dos Sintomáticos Respiratórios (SR), no diagnóstico precoce dos casos, no tratamento com esquema básico e/ou do acompanhamento próximo ao local de residência dos pacientes, facilitando o acesso e diminuindo a taxa de abandono ${ }^{2}$.

'Reservada' tem uma filha de 1 ano e 2 meses e realizou todo o acompanhamento pré-natal na unidade de saúde da família estudada, sendo este um fator pontuado como facilitador no acesso em busca do tratamento para TB.

Para 'Sociável', o vínculo estabelecido com a EqSF de referência construído pelo fato de ele já haver realizado acompanhamento para diabetes na unidade, além de tê-lo influenciado a buscar atendimento logo no aparecimento dos primeiros sintomas, demonstra a confiança que tem nos profissionais de saúde que o assistem, contribuindo para a aceitação do diagnóstico e do tratamento proposto. Ele gosta do atendimento prestado e enxerga a unidade de saúde da família como uma referência para resolução dos seus problemas de saúde.
O apoio dado pela sua irmã associado ao vínculo estabelecido e confiança no profissional de saúde fizeram com que 'Sociável' buscasse atendimento no local onde se sentia mais bem acolhido.

Já 'Tímido' reforça que as poucas vezes em que esteve na unidade de saúde foi apenas para realizar o acompanhamento do Programa Bolsa Família, mas reforça que sua família quando tem algum problema de saúde recorre ao atendimento oferecido pela clínica. Além disso, avaliou positivamente o atendimento recebido na unidade.

Apesar de possuir cadastro na clínica da família estudada há três anos e de ter iniciado outros dois acompanhamentos para TB nessa mesma unidade, 'Abatido' recorreu ao atendimento na UPA para resolução imediata do seu problema de saúde, e não na ESF. A partir do seu depoimento, observa-se que o vínculo com a unidade se estabeleceu a partir da adesão ao TDO, em que a Agente Comunitário de Saúde (ACS) responsável tem colaborado para a construção do elo entre este e o serviço de saúde.

'Esperta' demonstrou em seu relato que a unidade de saúde da família funciona como principal referência para o cuidado em saúde da sua família, porém, devido à percepção do agravamento do seu quadro e ao horário em que foi feita a procura pelo atendimento à saúde, o local onde foi realizada a primeira avaliação foi na UPA. A confiança e o vínculo estabelecido com a ACS responsável colaboraram para a busca de uma nova avaliação na ESF, possibilitando o início do tratamento em tempo oportuno e contribuindo para a adesão ao tratamento, por meio da realização do TDO.

'Responsável', visando à resolução do seu problema de saúde, mesmo não tendo buscado o primeiro atendimento na ESF, acionou os serviços públicos de saúde que conhecia e nos quais confiava.

Os participantes 'Sociável' e 'Abatido' apontaram alguns obstáculos relacionados com o acesso ao serviço de saúde, entre 
eles: a dificuldade para acessar a clínica da família, devido à localização geográfica e à debilidade física potencializada pela doença, gerando um gasto financeiro para o deslocamento. Esses usuários realizavam a tomada diária da medicação na unidade, porém apresentavam condições de saúde limitantes associadas ao perfil de hipossuficiência. Essas condições já lhes garantiriam o benefício social do RioCard, mas apenas 'Sociável' mencionou que já havia dado entrada nessa solicitação. Sendo assim, cabe à ESF atentar para as peculiaridades de cada situação e avaliar as limitações do usuário, visando à melhoria da condição de vida deste e buscando sempre facilitar o acesso e garantir a adesão ao tratamento ${ }^{21}$.

A acessibilidade aos serviços de saúde, que também aborda a distância percorrida pelo usuário para acessar a unidade de saúde, os obstáculos físicos existentes, limites ou facilidades de locomoção e os custos implicados nesse deslocamento são fatores que garantem a integralidade nos serviços de saúde, porém esta se torna comprometida quando não há o entendimento da existência dessas variáveis que limitam ou dificultam o acolhimento dos usuários nas portas de entrada da rede, podendo contribuir para o abandono ao tratamento ${ }^{22}$.

'Sociável' sinalizou que, devido à amputação sofrida em membro inferior esquerdo, passou a apresentar certa dificuldade para se deslocar, mas ao mesmo tempo necessita de curativos diários no local da amputação. Como nem sempre tem uma pessoa em casa que possa fazê-lo, combinou com a EqSF de comparecer à unidade pelo menos três vezes na semana. Entretanto, devido ao diagnóstico de $\mathrm{TB}$, ele tem vindo à unidade diariamente, pois também precisa realizar o TDO. O entrevistado queixou-se muito dessa situação, já que ainda não conseguiu adquirir seu RioCard e, com isso, na maioria das vezes, tem descido e subido a pé a ladeira que dá acesso à unidade de atenção básica. Disse que, às vezes, tem que pedir uma carona aos motoristas de Kombi que circulam pela comunidade e que nem todos respeitam a legislação de uma gratuidade para maiores de 60 anos, e isto tem gerado alguns aborrecimentos. Para não se indispor, às vezes, desce a pé e paga um transporte para subir.

'Abatido' relatou que, no início do tratamento, devido a sua debilidade física, apresentava dificuldade para se deslocar até a unidade, mas que mesmo assim não deixou de comparecer ao serviço para tomar o medicamento. Sendo a localização geográfica um importante critério para o acesso aos serviços de saúde, cabe à EqSF responsável avaliar as limitações do indivíduo, buscando sempre facilitar o acesso ao usuário e garantir a sua adesão ao tratamento.

Outro ponto observado nas narrativas foi o desconhecimento dos serviços oferecidos pela clínica da família influenciando no atraso do início do tratamento adequado de alguns usuários entrevistados, no entanto, após iniciado, o vínculo estabelecido com a EqSF tornou-se fundamental para a manutenção do tratamento.

Novamente, o TDO apresentou-se como uma estratégia eficaz para construção do vínculo usuário-profissional, oportunizando sanar dúvidas a respeito da doença e do tratamento e propiciando o encorajamento do paciente adiante da doença. Na fala de 'Responsável', os profissionais mencionados foram o médico da ESF, a ACS responsável e a auxiliar de farmácia da unidade.

Nota-se pela trajetória terapêutica adotada pelo usuário ‘Agitado' que o tempo de cadastro na ESF também não interferiu nas suas escolhas em se tratando de resolução dos seus problemas de saúde. Essa situação evidencia uma fragilidade da ESF no que tange ao acompanhamento da população adscrita. No entanto, após iniciado o tratamento, a relação com o ACS responsável pelo TDO possibilitou a construção de vínculo, o que tem influenciado no enfrentamento positivo da doença.

Como pode ser observado nas narrativas dos entrevistados, os ACS que são sujeitos 
que ocupam uma posição diferencial no território, por estarem em intercâmbio com estruturas locais e circularem por espaços externos ao comunitário, estabeleceram uma abordagem que conseguiu atingir o objetivo principal de sua função, que é servir como elo entre a unidade de saúde e usuário, contribuindo de forma efetiva para a adesão ao tratamento da doença.

\section{Os diversos capitais da rede}

Os dados coletados permitiram inferir que o capital social e o cultural contribuem e interagem diretamente com o capital econômico para fortalecer a determinação e reprodução da TB, visto que a perpetuação dessa doença está vinculada a populações que vivem em condições de pobreza, aglomeração humana e falta de saneamento básico.

As narrativas analisadas mostraram que ter uma história anterior de adoecimento, seja pela TB ou por outra doença, assim como conviver com pessoas que já estiveram nessa situação, representou um ganho de capital cultural, visto que o conhecimento adquirido pelo acúmulo de informação se mostrou fundamental para busca ao atendimento, aceitação da doença e adesão ao tratamento atual.

O capital cultural, entendido como aquele que acumula capacidades intelectuais e culturais, sob a forma de estado incorporado, presume um processo de inculcação e assimilação, não podendo ser transmitido rapidamente, mas sim de forma instintiva, mantendo-se marcado pela condição primitiva de aquisição. A mensuração do capital cultural de maneira menos inexata se dá ao levar em consideração o tempo de aquisição que engloba a educação familiar, o investimento familiar ${ }^{\mathbf{2 3}}$.

'Sociável' possui uma história patológica pregressa que, de certa forma, influenciou na busca pelo cuidado em saúde e enfrentamento da TB. Não que tivesse pensado em estar com TB desde o aparecimento dos primeiros sintomas, mas o fato de ter vivenciado situações de adoecimento frequente na infância, de conviver com a diabetes mellitus desde 2008, de ter sofrido uma amputação no pé esquerdo em 2016, de conhecer pessoas que já tiveram TB contribuiu para uma melhor aceitação do diagnóstico e adesão ao tratamento.

'Tímido' demonstra que seu histórico familiar contribuiu para a boa aceitação do diagnóstico, visto que a TB já havia acometido vários integrantes da sua família, inclusive uma das suas irmãs. Esta irmã concluiu o tratamento para TB há 3 anos, obtendo alta por cura e foi quem, a partir do seu conhecimento prévio, suspeitou que ele pudesse estar também com TB, inclusive sinalizando essa possibilidade ao médico que prestou o primeiro atendimento.

O baixo poder aquisitivo, o reduzido nível de escolaridade e o local de procedência dos entrevistados e de seus pais, tendo-os como primeiros educadores, são determinantes sociais que reforçam a vulnerabilidade desses sujeitos ao adoecimento por TB, mas ao mesmo tempo, considerando as diferentes formas de enfrentamento da doença, mostram o capital cultural como um ganho individual, como um conhecimento legitimado aplicado ao cotidiano e adquirido durante o processo de socialização.

O processo de adoecimento gera uma série de sentimentos e reflexões no indivíduo, como medo, apreensão, ameaça, incerteza, fazendo com que pense nas vulnerabilidades e, até mesmo, em questões relacionadas com a morte.

A TB é uma doença infectocontagiosa que possui um tratamento de longa duração, e isso exige que o indivíduo aprenda a lidar com essa nova situação para que, dessa forma, consiga compreender o processo saúde/doença e, assim, identificar, evitar ou prevenir complicações. Por esse ângulo, a adesão ao tratamento é um fator relevante para o sucesso do cuidado e um desafio tanto para a ESF, que, de certa forma, precisa operacionalizar esta adaptação, quanto para os pacientes ${ }^{2}$.

Pensando sob essa perspectiva, as 
narrativas de 'Sociável' e 'Esperta' mostram que a aceitação da doença, e até mesmo a percepção do processo de adoecimento, apresentou-se de forma particular, não sendo possível determinar padrões para o processo de saúde/doença na TB, mas sim compreender que cada indivíduo possui sua singularidade e recebe influência do meio em que vive, influenciando assim o enfrentamento da doença.

No entanto, aspectos coletivos podem ser também destacados, na medida em que todos os entrevistados são moradores de bairro periférico, vivem em situação de vulnerabilidade social e ambiental, possuem origem pobre, não trabalham ou quando trabalham é na informalidade. O enfrentamento dessas vulnerabilidades e reprodução dessas famílias dá-se por intermédio de uma multiplicidade de caminhos que indicam os deslocamentos possíveis em um terreno de antigas e novas formas de pobreza ${ }^{\mathbf{2 4}}$.

Outra questão presente nos depoimentos foi a percepção do caráter estigmatizante da doença. Isto se deve ao fato de a doença estar associada a precárias condições de vida, mas também aos excessos, em que as situações de recaída frequentes nesses grupos, bem como as crenças do imaginário popular, geram incertezas acerca da cura. Devido ao preconceito sofrido, o paciente passa a ter dificuldade em assumir e em seguir o tratamento, e a ESF passa a ter dificuldade em realizar o devido acompanhamento da doença ${ }^{2}$.

'Sociável' sentiu medo quando recebeu o diagnóstico de TB, pois achava que o tratamento da doença fosse algo mais difícil, mas quando foi informado que consistia em tomar uma medicação oral diariamente por 6 meses, acalmou-se.

Lidar com o diagnóstico da TB não foi uma situação fácil para 'Esperta'. O comprometimento com a autoimagem, o medo de ficar internada, de ser discriminada foram questões que surgiram ao receber o diagnóstico, as quais ela teve que aprender a enfrentar nesse processo de adoecimento.
'Responsável' relatou que, ao receber o diagnóstico, ficou muito preocupado e com medo, logo pensou na família, no trabalho e na possibilidade de ficar internado; mas depois, com o apoio da esposa e da ESF, foi percebendo a melhora do seu quadro clínico e aceitou melhor o tratamento.

Em relação à percepção do caráter estigmatizante da doença, 'Responsável' relatou que evitava andar na rua com a máscara cirúrgica para não ser questionado e que ficou chateado quando um dia, ao entrar na clínica para tomar a medicação diária do tratamento, um membro da ESF solicitou que colocasse a máscara. Disse que havia sido orientado quanto ao uso da máscara em ambientes fechados, mas não imaginou que tivesse que fazer uso também dentro da unidade.

Um aspecto observado nas falas dos usuários foi que o uso da máscara causou desconforto e gerou preconceito, porém sua obrigatoriedade de uso era exigida apenas dentro da unidade de saúde. Isso demonstra que os usuários não compreenderam o caráter transmissível da doença, pois eles deixavam de usar o artefato nos demais espaços públicos.

Sendo assim, pensar em estigma social e preconceito e como cada indivíduo teve que lidar com o diagnóstico da TB remete aos capitais em jogo nas redes dos usuários, visto que os capitais, sejam eles econômico, social ou cultural, determinam a posição social dos atores, influenciam nas atitudes e na forma de lidar com a doença, podendo exercer uma função protetora ou potencializadora do sofrimento no processo de adoecimento de cada indivíduo.

\section{Conclusões}

O estudo das redes sociais dos usuários portadores de TB possibilitou compreender a busca pelo cuidado em saúde como um processo que envolve diversos aspectos que atuam de maneira distinta sobre os indivíduos. 
As narrativas possibilitaram identificar particularidades e sistematizar como se deu o enfrentamento da doença para cada usuário entrevistado, iniciando pela percepção dos primeiros sintomas e encerrando com a influência exercida pelas redes sociais nesse processo.

A percepção dos primeiros sintomas relacionados com a TB não gerou a busca imediata à unidade de saúde da família, mesmo esta presente no território há 7 anos. De modo geral, após o uso da medicina caseira ou automedicação, os serviços de pronto atendimento apareceram como primeira escolha de atendimento do usuário visando à resolução imediata do seu problema de saúde. Além da falta de vínculo com a EqSF, essa situação evidenciou a falta de conhecimento e reconhecimento dos serviços oferecidos pela unidade de saúde da família.

As redes primárias demonstraram seu potencial como reais influenciadoras para a busca pelo cuidado em saúde, atuando em todas as etapas do processo de adoecimento e enfrentamento da doença. Já as redes secundárias mostraram sua relevância nesse processo a partir das ações de controle da TB, com destaque para o TDO, que possibilitou a construção do vínculo profissional-usuário e, com isso, o fortalecimento do usuário para aceitação da doença e adesão ao tratamento.

$\mathrm{Na}$ maioria dos casos, os atores da rede secundária só foram mencionados nas redes dos usuários após o início do tratamento, reforçando a necessidade de revisão das práticas e processos de trabalho, despertando a reflexão sobre o papel das EqSF nos territórios, principalmente no que tange à educação em saúde como uma estratégia potencial para o aumento de capital cultural dos usuários.

O entendimento dos conceitos capital econômico, capital cultural e capital social possibilitou compreender a mobilização de recursos nas redes sociais viabilizando a circulação da informação e do conhecimento em prol do cuidado em saúde.

Em suma, estudar as redes sociais dos usuários portadores de TB permitiu vislumbrar o potencial da estrutura das redes para o cuidado em saúde, reforçando a importância de políticas de inclusão dos usuários nos serviços de saúde e do estreitamento de vínculo entre as redes primárias e secundárias. 


\section{Referências}

1. Brasil. Ministério da Saúde. Secretaria de Vigilância em Saúde. Departamento de Vigilância das Doenças Transmissíveis. Plano nacional pelo fim da tuberculose. Brasília, DF: Ministério da Saúde; 2017.

2. Brasil. Ministério da Saúde. Secretaria de Atenção à Saúde. Departamento de Atenção Básica. Tuberculose na Atenção Primária à Saúde. 2. ed. Brasília, DF: Ministério da Saúde; 2011.

3. Santos TMMG, Nogueira LT, Santos LNM, et al. $\mathrm{O}$ acesso ao diagnóstico e ao tratamento de tuberculose em uma capital do nordeste brasileiro. Rev Enferm UERJ [internet]. 2012 jul-set [acesso em 2017 set 12]; 20(3):300-305. Disponível em: http:// www.e-publicacoes.uerj.br/index.php/enfermagemuerj/article/view/2542/2873.

4. Nogueira JA, Oliveira LCS, Sá LD, et al. Vínculo e acesso na estratégia saúde da família: percepção de usuários com tuberculose. Rev Rene [internet]. 2012 [acesso em 2016 set 16]; 13(4):784-793. Disponível em: http://pesquisa.bvs.br/aps/resource/pt/ lil-679896.

5. Brasil. Ministério da Saúde. Secretaria de Vigilância em Saúde. Departamento de Vigilância Epidemiológica. Manual de recomendações para o controle da tuberculose no Brasil. Brasília, DF: Ministério da Saúde; 2011.

6. Cabral ALLV, Martinez-Hemaez A, Andrade EIG, et al. Itinerários terapêuticos: o estado da arte da produção científica no Brasil. Ciênc Saúde Colet [internet]. 2011 [acesso em 2016 jun 3]; 16(11):4433-4442. Disponível em: http://dx.doi.org/10.1590/41381232011001200016 .

7. Marteleto RM. Redes e configurações de comunicação e informação: construindo um modelo interpretativo de análise para o estudo da questão do conhecimento na sociedade. Investig Bibliotecológica [internet]. 2000 jul-dez [acesso em 2016 set 30]; 14(29). Disponível em: http://ridi.ibict.br/handle/123456789/189.
8. Stotz EN. Redes sociais e saúde. In: Marteleto RM, Stotz EN, organizadores. Informação, saúde e redes sociais: diálogos de conhecimentos nas comunidades da Maré. Rio de Janeiro: Fiocruz; Belo Horizonte: UFMG; 2009. p. 26-42.

9. Marteleto RM, Tomaél MI. A metodologia de análise de redes sociais (ARS). In: Valentim MLP, organizador. Métodos qualitativos de pesquisa em ciência da informação. São Paulo: Polis; 2005. p. 81-100.

10. Amendola F, Oliveira MAC, Alvarenga MRM. Influência do apoio social na qualidade de vida do cuidador familiar de pessoas com dependência. Rev Esc Enferm USP [internet]. 2011 [acesso em 2016 jun 4]; 45(4):884-889. Disponível em: http://www.scielo.br/scielo.php?script=sci_arttext $\&$ pid=S0080$-62342011000400013 \& \operatorname{lng}=\mathrm{en} \& \mathrm{nrm}=$ iso.

11. Alves PCB, Souza IM. Escolha e avaliação de tratamento para problemas de saúde: considerações sobre o itinerário terapêutico. In: Rabelo MC, Alves PCB, Souza IM. Experiência de doença e narrativa. Rio de Janeiro: Fiocruz; 1999. p. 125-138.

12. Santos CW, Farias Filho MC. Agentes Comunitários de Saúde: uma perspectiva do capital social. Ciênc Saúde Colet [internet]. 2016 maio [acesso em 2016 jun 23]; 21(5):1659-1668. Disponível em: http:// www.scielo.br/scielo.php?script=sci_arttext\&pid=“ RESERVADA"413-81232016000501659\&lng=en\&nr $\mathrm{m}=$ iso.

13. Marteleto RM, Pimenta RM. Pierre Bourdieu e a produção social da cultura, do conhecimento e da informação. Rio de Janeiro: Garamond; 2017.

14. Plataforma Subpav. [acesso em 2017 jan 26]. Disponível em: http://subpav.org/cnes/cnes_eq_cobertura_listar_2016.php.

15. Glat R. Somos iguais a você: depoimentos de mulheres com deficiência mental. Rio de Janeiro: Agir; 1989. 
16. Andrade RLP, Scatolin BE, Wysocki AD, et al. Diagnóstico da tuberculose: atenção básica ou pronto atendimento? Rev Saúde Pública [internet]. 2013 dez [acesso em 2017 set 17]; 47(6):1149-1158. Disponível em: http://www.scielo.br/scielo.php?script=sci arttext\&pid=S0034-89102013000601149\&lng=en\& nrm=iso.

17. Beraldo AA, Arakawa T, Pinto ESG, et al. Atraso na busca por serviço de saúde para o diagnóstico da tuberculose em Ribeirão Preto (SP). Ciênc Saúde Colet [internet]. 2012 nov [acesso em 2012 set 17]; 17(11):3079-3086. Disponível em: http://www.redalyc.org/articulo.oa?id=63024420024.

18. Souza CTV, Natal S, Rozemberg B. Comunicação sobre prevenção da tuberculose: perspectivas dos profissionais de saúde e pacientes em duas unidades assistenciais da Fundação Oswaldo Cruz, Rio de janeiro. Rev Bras Pesq Ed Ciênc [internet]. 2005 [acesso em 2016 set 16]; 5(1):78-92. Disponível em: https://www.arca.fiocruz.br/handle/icict/18046.

19. Valla VV. A crise de interpretação é nossa: procurando compreender a fala das classes subalternas. Educ Realidade. 1996; 21(2):177-190.

20. Serapioni M. O papel da família e das redes primárias na reestruturação das políticas sociais. Ciênc Saúde Colet [internet]. 2005 [acesso em 2017 set 12]; 10(sup):243-253. Disponível em: http://dx.doi. org/10.1590/413-81232005000500025.
21. Brasil. Ministério da Saúde. Secretaria de Vigilância em Saúde. Departamento de Vigilância Epidemiológica. Tratamento diretamente observado (TDO) da tuberculose na atenção básica: protocolo de enfermagem. Brasília, DF: Ministério da Saúde; 2011.

22. Engel RH, Weiller TH, Farão EMD, et al. Acessibilidade geográfica e organizacional: obstáculos entre usuários com tuberculose e os serviços de saúde. Rev Enferm UFSM [internet]. 2013 out [acesso em 2016 set 30]; 3(2):307-314. Disponível em: https:// periodicos.ufsm.br/reufsm/article/view/8494.

23. Bourdieu P. O capital social: notas provisórias. In: Catani A, Nogueira MA, organizadores. Escritos de Educação. 9. ed. Petrópolis: Vozes; 2007.

24. Cunha MB, Frigotto G. O trabalho em espiral: uma análise do processo de trabalho dos educadores em saúde nas favelas do Rio de Janeiro. Interface Comun Saúde Educ [internet]. 2010 out-dez [acesso em 2018 jan 1]. Disponível em: http://www.redalyc. org/articulo.oa?id=180115837022.

Recebido em 04/01/2018 Aprovado em 04/03/2018

Conflito de interesses: inexistente

Suporte financeiro: não houve 